\title{
Zambrano, Pilar y Cianciardo, Juan, La inteligibilidad del Derecho, Buenos Aires, Marcial Pons, 2019.
}

Pilar Zambrano y Juan Cianciardo se proponen a lo largo de los cuatro capítulos de La inteligibilidad del Derecho realizar una defensa de la conexión entre el Derecho y la Moral capaz de afirmar de modo consistente la autonomía y la relevancia de los dos órdenes normativos. La originalidad del texto descansa, por un lado, en la claridad y en la profundidad con la que los autores dejan evidenciados los errores filosóficos en los que han incurrido algunos de quienes se han propuesto dar con una solución al problema planteado y, por otro lado, en la capacidad que tienen para brindar salidas alternativas a las ofrecidas por los juristas criticados.

Para lograr su cometido, Zambrano y Cianciardo realizan un recorrido que podríamos desglosar en tres niveles: un primer nivel en el que se asientan las bases del discurrir jurídico-filosófico de la obra, una vez que se deja evidenciado que los rasgos más sobresalientes de los sistemas jurídicos contemporáneos solo pueden fundamentarse y validarse en relación a un orden moral independiente (OMI) del Derecho y de cualquier praxis humana; un segundo nivel en el que se analiza desde la óptica de Carlos Nino y John Finnis cuál es la relevancia, entonces, de un Derecho cuya validez depende en último término de su adecuación a la Moral, y un tercer nivel en el que se estudia cómo debe ser el funcionamiento de una interpretación jurídica que está conectada con la moralidad.

Siguiendo el plan diseñado, el primer capítulo lo dedican al análisis de la cultura de derechos. En concreto, centran su atención en los siguientes cinco caracteres: (a) el hecho de que los Derechos Humanos son reconocidos y no constituidos, (b) el hecho de que la puja entre monismo y dualismo se resuelve en último término atendiendo a criterios axiológicos, (c) el hecho de que las Constituciones contienen principios, (d) el hecho de que existe un principio de proporcionalidad y (e) el hecho de que existe un principio de razonabilidad. Para ellos, la presencia de estos rasgos en los ordenamientos jurídicos actuales pone de manifiesto que (i) existe un orden axiológico y normativo independiente (OMI) de la cultura de derechos y de toda praxis humana y que (ii) la validez del orden jurídico depende de su adecuación a 
este orden moral, lo cual supone que su contenido ha de ser perfectamente inteligible, puesto que de lo contrario no cabría la posibilidad de pretender tal adecuación.

Los motivos que conducen a los autores a sostener ambas pretensiones se deducen de un análisis crítico sobre lo que la existencia de cada uno de los caracteres significa. Así, por ejemplo, afirman que el hecho de que los Derechos Humanos sean reconocidos y no constituidos significa que su creación no viene dada por el ordenamiento jurídico positivo sino, más bien, por un orden normativo que es independiente del Derecho y de toda praxis humana. A su vez, al jugar las razones que fundamentan la presencia de unos mandatos de optimización en las Constituciones concluyen que solo puede justificarse si se acepta que los criterios axiológicos recogidos en ellos (justicia, solidaridad, paz social, etc.) son, además de per se inteligibles, buenos y queridos por los destinatarios de la norma -de allí que lo denominen orden moral-.

Con estos y otros ejemplos Zambrano y Cianciardo van dejando evidenciado que la cultura de derechos actual se apoya consciente o inconscientemente en una Moral. Y agregan todavía una cosa más: de la mano de Robert Alexy sostienen que la conexión del Derecho no es simple y llanamente con "un orden moral" sino que es, en realidad, "con la moral correcta". El problema que surge con esta afirmación puede sintetizarse con la pregunta que constituye el objeto de estudio del segundo y del tercer capítulo: si el Derecho depende en última instancia de la Moral, ¿por qué no guiarnos simplemente por ella?

Carlos Nino ya abordó este problema y aportó una respuesta que en $L a$ inteligibilidad del Derecho se somete a examen para determinar si resuelve o no el asunto en cuestión. Lo que el jurista argentino propone, movido por un escepticismo ético, es que el Derecho mantiene su relevancia aun cuando remite a la Moral por el hecho de que el contenido de esta última permanece oculto hasta tanto el orden jurídico no lo determine. De acuerdo con su teoría, al no ser el contenido moral perfectamente cognoscible, la única manera de acercarse fidedignamente a aquello que ordena la moralidad sería implementando un sistema epistemológico que lo permita, el cual, para Nino, estaría en el "discurso moral". Según este método, los principios morales válidos serían aquellos que se escogiesen luego de haberse realizado una discusión que haya estado sometida a unas reglas formales.

Con esta propuesta Nino pretendería dejar salvada la relevancia del Derecho: como los mandatos que expresa la moralidad se conocen a través del discurso moral, que encontraría su sucedáneo en los procesos democráticos como el parlamentario -que se expresa por boca del Derecho-, resultará que la existencia de un orden jurídico es indispensable para conocer el contenido moral. No obstante, para Zambrano y Cianciardo esta solución 
epistemológica incurre en varios errores: en primer lugar, consideran que no logra demostrar la independencia de los dos órdenes normativos, puesto que hace depender el contenido moral del contenido jurídico, de manera que se terminan confundiendo en una misma realidad el Derecho y la Moral; en segundo lugar, afirman que se incurre en una clara circularidad porque se pretende adecuar el orden jurídico a un orden moral que, en última instancia, se termina conociendo a través del orden jurídico y, en tercer lugar, sugieren que al negarse la inteligibilidad propia del contenido moral se termina forzando un constructivismo ético que no hace más que ahogar las iniciativas de Nino.

Es por estas razones que los autores prefieren dedicar el tercer capítulo a analizar la teoría de un reconocido iusnaturalista que acepta la posibilidad real y efectiva de que la razón humana pueda acceder al contenido moral, a saber: John Finnis. Para este profesor de Oxford, el ser humano estaría inclinado hacia unos bienes humanos básicos que, de alcanzarse armónicamente, permitirían una realización humana integral -la eudaimonía, en términos aristotélicos, o "felicidad", en términos modernos-. La Moral, según esta perspectiva, mandaría en todo momento a actuar en busca del florecimiento humano, lo cual exigiría por parte del agente una deliberación prudencial al momento de obrar que le permita acertar en la decisión que lo conduzca a realizar todos los bienes humanos básicos de forma armónica.

Sin embargo, pese a reconocer que lo moralmente correcto es susceptible de ser conocido y, por ende, de guiar la conducta humana, Finnis entiende que no puede prescindirse del Derecho, puesto que para poder perseguir la realización humana integral -que es querida por todos en virtud del bien humano básico de la razonabilidad práctica- es necesario que exista una comunidad política debidamente organizada por una autoridad, lo cual no puede lograrse sin la existencia de un orden jurídico previamente instituido. Así, mientras la Moral indicaría simplemente qué debe hacerse, el Derecho -además de indicarlo- establecería las condiciones óptimas para que las personas puedan, en efecto, florecer humanamente.

Sobre este aspecto de la teoría del oxoniense, Zambrano y Cianciardo concuerdan plenamente. No sucede así, en cambio, con el nivel de exclusividad tan alto que este le otorga a las normas jurídicas. Para Finnis, el Derecho ofrece razones excluyentes para la acción, esto significa que cuando el destinatario se encuentra frente a una norma jurídica debe aceptar sin más que lo mandado por ella constituye el mejor modo de alcanzar el bien común. Para los autores, este modo de entender el comportamiento del ciudadano frente al Derecho es, además de poco acorde con la realidad, imposible que se materialice en la práctica. Consideran que dotar con un nivel tan alto de exclusividad a las normas jurídicas es contrario a la misma naturaleza del razonamiento práctico. Por ello, aunque se adhieran fuertemente a la 
propuesta de los bienes humanos básicos, no tienen reparos en separarse de este punto por considerarlo inadecuado.

Por último, después de haber dado respuesta al problema de la relevancia de un Derecho que remite a la Moral, dedican el cuarto capítulo a explicar cómo debe ser una interpretación jurídica que está conectada con la moralidad. Para hacer frente a su propósito identifican, primero, cuáles han sido los errores teóricos de Kelsen y Dworkin en relación a los criterios que deben regir la creación y la interpretación normativa y, segundo, proponen cuál es el mejor modo de superarlos. En este orden de ideas, afirman que la tesis kelseniana de la autonomía semántica no puede ser aceptada porque, tanto en la creación como en la interpretación de las normas jurídicas, abre las puertas al legislador y al juez para que actúen con discrecionalidad. Y es que, de acuerdo con esta teoría, de los innumerables significados que un parlamentario puede escoger para definir los hechos brutos, la inclinación por una tipología específica dependería de criterios no regulables, es decir, arbitrarios, por lo que su interpretación seguiría la misma suerte.

De un modo similar, la solución de Dworkin no logra escapar de las acertadas críticas de Zambrano y Cianciardo. Pese a que reconocen que la teleología como criterio de creación e interpretación normativa constituye una salida racional a la arbitrariedad permitida por Kelsen, refieren que pretender interpretar el sistema jurídico considerado in totum para acortar el margen de discrecionalidad del juez, en realidad, debido a su complejidad y extensión, genera el efecto contrario. A su vez, sugieren que el método de interpretación correcta de la norma jurídica incurre en una tautología porque, cuando el juez busca determinar cuáles son los fines y valores involucrados en el caso en cuestión para compararlos con los que se encuentran ya en el ordenamiento jurídico, en el fondo, se está remitiendo al juez a que interprete otras normas jurídicas, lo cual es una clara circularidad.

Para superar los inconvenientes denunciados, los autores proponen la adopción de una teoría semántica realista como la de Putnam y Kripke, según la cual las realidades a las que se refiere el lenguaje serían perfectamente inteligibles. De acuerdo con esto, si el Derecho en su teleología pretende la protección de unos bienes humanos básicos que son per se comprensibles, resultará que la correcta interpretación de las normas jurídicas deberá buscarse en las realidades referidas y no en los significados del texto. De allí que Zambrano y Cianciardo afirmen que la referencia tiene prioridad sobre el significado. Así, la posibilidad de que haya arbitrariedad en el proceso de creación e interpretación normativa quedaría disminuida: las realidades tendrían sus significados propios que ni el legislador ni el juez podrían alterar.

Con estos argumentos los autores logran sostener a lo largo de toda la obra la relevancia de un Derecho que remite a un orden moral independien- 
te de él y de toda praxis humana y consiguen, no sin esfuerzo, demostrar de forma más que evidente los errores lógicos de la teoría de Nino sobre la paradoja de la irrelevancia, los excesos ambiciosos de la teoría de Finnis sobre el nivel de exclusividad de las razones que mueven a obedecer el Derecho y los riesgos y circularidades de las teorías de Kelsen y Dworkin -respectivamente- sobre los parámetros que deben regir la creación e interpretación normativa.

Los razonamientos de Zambrano y Cianciardo, en un contexto de enorme fragmentación ética como el actual, son particularmente pertinentes y dignos de ser conocidos y debatidos. Haber argumentado de modo sólido y profundo que sin la existencia de un orden moral independiente e inteligible la justificación de la relevancia del orden jurídico se torna en una quimera inalcanzable -incluso para iusfilósofos tan doctos y sofisticados como los que se trabajan en el libro-, permite afirmar que La inteligibilidad del Derecho es un trabajo indispensable para todo interesado en los temas que en él se tratan.

JoRGE MACHín 